\title{
Reproducing the general through the local: Lessons from poverty research
}

\begin{abstract}
Central to research into the conduct of everyday life are issues of generalisation. This chapter focuses on three interrelated forms of generalisation, which invoke issues around how macro level structures and intergroup relations are reproduced through micro level situations. First, theoretical generalisation constitutes efforts to enlarge the significance of small-scale exemplars by relating local insights to the broader body of academic knowledge. Second, referential generalisation involves relating everyday artefacts produced by our research participants to the broader social context and intergroup relations. Third, empathetic generalisation involves promoting witnessing, recognition and empathy towards people experiencing poverty by people who are not living in poverty. These three forms of generalisation are central to the development of action strategies to address issues of poverty.
\end{abstract}

Throughout or disciplinary history, psychologists have responded to general issues of poverty through engagements with particular community settings (Hogetts et al., 2010; Hodgetts \& O'Doherty, 2018). Accompanying this early focus on everyday poverty were concerns regarding the consequences of inequitable social arrangements (Jahoda et al., 1933, 1992). Today, poverty researchers continue to document how the general (including political-economic systems that generate poverty) is reproduced through the particular (persons and communities). Scholarship in this area speaks to the [dis]functioning of societal structures in local settings. It draws on a dialectical understanding of society to explore how the general becomes entangled within the particular. Articulating such a societal perspective on the quotidian, Simmel (1910/1978: 99) writes:

...society is a structure that transcends the individual, but that is not abstract. Historical life thus escapes the alternative of taking place either in individuals or in abstract generalities. Society is the universal which, at the same time, is concretely alive.

Building on Simmel's insight, our understanding of the quotidian does not require a choice between the particular/personal and the general/abstract. As Simmel argues, each historic moment contains aspects of personal lived experience and society at large. This orientation enables us to move out beyond everyday experiences of hardship and into consideration of the ways in which broader societal relations take form in everyday lives in adversity. 
Accordingly, we approach everyday life as a domain of human interaction where dynamic facets of people's lives come together, often in concert with those of people around them in ways that reproduce social structures (Hodgetts et al., 2018). Everyday life is where human experience and action exists simultaneously in personal and societal life (Holzkamp, 1995/2016). The quotidian constitutes a social realm through which small acts are cumulatively combined to forge inhabited social environments that manifest broader societal structures. As Dreier (2016, p. 21) notes: "Persons include simple routines in more extensive personal arrangements of their conduct of everyday life that they establish in relation to the societal arrangements of everyday social practice". Personal acts such as turning off a heater to save power, eating rotten food, or sleeping on the streets take on significance as social practices through which societal inequalities and marginality are reproduced (Halkier, 2011; Halkier \& Jensen, 2011). Such practices often enact phronetic or practically-oriented, tacit, provisional, malleable and experiential knowledge that people develop in response to situations of poverty (cf., Flyvbjerg et al., 2012). These everyday acts can appear insignificant and unremarkable on the surface. It is when we consider such everyday acts in the context of broader relational configurations that their societal significance comes to light.

Concisely, supporting the philosophical position that the specific resembles the general, but is not reducible to it (Simmel, 1903/1997), we work to extract general insights out of detailed considerations of local practices and objects (Davis, 1973; Frisby, 1981). Because the general is already entangled within the particular, our approach is anchored in lived experiences of adversity whilst speaking to the broader societal aetiology of everyday poverty (Hodgetts \& Stolte, 2017). Central is a conceptual shift from the specific out towards what Goffman (1963) refers to as the backstage of social phenomenon. This backstage is populated by intergroup relationships that drive wealth concentration into the hands of the few at the expense of growing numbers of people in countries such as New Zealand (Hodgetts \& Stolte, 2017). We seek to convey insights into particular scenes featuring our participants in a manner that enables readers to recognise the societal forces at play.

In many respects, we have come to understand this approach as similar to that of early impressionist painters and earlier impressionist social scientists such as Georg Simmel (Davis, 1973; Frisby, 1981). These artists focused on everyday subject matter and worked to move our gaze with broad strokes from local scenes out to the social universe at play in situated happenstance. As we work our way out from experiences of hardship to the broader social structures at play, we also move out beyond the tendency in ruling psychology to individualise social problems, such as poverty as magically the product of personal inadequacies (Hodgetts \& Stolte, 2017). Instead, we locate the aetiology of poverty primarily in broader dysfunctional intergroup relations that have been shaped by greed rather than 
need. Rather than trying to capture or duplicate a frozen moment plucked from 'real' lives, like impressionist painters we aim to offer readers an overall impression of the dynamics of everyday poverty. The value of such impressions is not whether or not they represent an actual stable reality (assuming for a moment that this might is even possible). Value resides in offering more affluent audiences who have not experienced poverty themselves understandings and insights that enable them to understand and empathise with people who are living in poverty. In producing such impressions, we move constantly between specific descriptions of a local scene and theoretical abstractions that take us into more general arguments about the everyday impoverished situations in which our participants find themselves. The result is an intensified picture of actuality that is comprised, at least metaphorically of incomplete brush strokes that hint at, rather than capture everyday poverty.

This chapter exemplifies our developing impressionist orientation in relation to the use of visual exercises designed to aid our participants in sharing their experiences of poverty with us. These activities are designed to allow participants to 'show' and 'tell' us about their everyday lives (Hodgetts, Radley \& Chamberlain, 2007). Instead, of viewing the resulting drawings or photographs as hard 'data' that conveys set, concrete evidence of reality, we view these materials as offering incomplete insights that often hint at, but never fully capture what everyday poverty is like for people. In this chapter we will demonstrate how the mimetic objects produced by our research participants can be understood as empirically valuable agentive efforts to re-assemble, mimic, imitate, approximate, partially express and render more tangible their experiences of hardship and the material ramifications of inequitable social structures (Hodgetts, et al., 2018). In extending our account of impressionistic scholarship, we set out three interrelated aspects of generalisation. First, our efforts involve theoretical generalisation or bringing conceptual abstractions to bear as we interpret what participants' show and tell us about their experiences of poverty. Second, we explore the broader societal structures and relationships that shape personal experiences of hardship or what we term referential generalisation. Third, empathetic generalisation is central to our efforts to cultivate compassion among people whose decisions impact the lives of our participants.

\section{Theoretical generalisation}

Theoretical generalisation has been considered at some length in scholarly discussions regarding qualitative research (Fine, 2006; Halkier, 2011), and is central to approaches such as grounded theory that seek generate theory from research (Strauss \& Corbin, 1994). For 
us, efforts to generalise through theory are less about developing new theory from qualitative data and are more about bridging the space between everyday human experience and broader and existing philosophical abstractions (cf., Simmel, 1903/1997). We draw on theory in order to situate and interpret systemically the everyday experiences of poverty with which we are grappling through research. As we recount below, theoretical generalisation involves bringing images produced by participants into conversation with existing theoretical abstractions in order to crack these artefacts open, and to develop our interpretations of depicted events and relationships (Halkier, 2011). For example, such an approach enables us to better comprehend how neoliberalism, which has been theorised to increase poverty and reduce societal supports for people in need is reproduced everyday when people try to access services. We also draw on theoretical generalisation to make sense of what research participants are doing when they attempt to reconstruct and communicate their experiences of hardship visually during research by drawing on philosophical concepts such as mimesis (Benjamin, 1933/1978; 1982). Whether focused on content (neoliberalism) or process of picturing (mimesis), theoretical generalisation involves adopting the position of the researcher as bricoleur (Lévi-Strauss, 1962) by bringing together insights from everyday experiences with insights from theory to create new impressions of poverty and its lived implications.

To demonstrate our orientation towards theoretical generalisation we refer to an example from a previous research project on urban poverty in Auckland. As part of the Family100 project (Hodgetts et al., 2014) we asked participants to draw and talk about the social services they came into contact with over the previous two weeks. Many of the participants drew cluttered service maps. For example, Figure one depicts numerous agencies this participant engaged with, while the jagged lines represent stressful or discordance interactions with many of these organisations. For us, this image is not simply a dispassionate chart of the everyday interactions of an individual in need. The significance of Figure one extends beyond the page, as a depiction of a chaotic and dysfunctional welfare sector, which Waquant (2009) has theorised as 'penal welfare'. This service map illustrates how welfare no longer functions as a coherent 'system'. Instead, when positioned as denizens (Bauman, 2004), people facing poverty must navigate a raft of loosely connected agencies that are overly bureaucratic, punitive and demanding in orientation towards them (Hodgetts et al., 2014). This often results in a high degree of time wasting and experiences of futility that add to the stress of poverty (Hodgetts \& Stolte, 2017). As Hayley states:

It's the run around. I'm pretty organised and even if you do have...the paperwork that's required, there is still one thing they will demand you get... So you've got to 
rebook your appointment, use up more gas to go and run around, or more money for the buses.

Above, Hayley invokes time wasting as a core activity in everyday scenes where people attempt to access welfare supports. Typically, in order to access welfare payments from a government agency people must obtain certification from a budgeter, even though the government agency already knows what their income is because they are the one's paying it. Once this task is completed, a person is then often asked for additional documentation from sources such as power companies to further prove their need for financial assistance. Such tasks all take time, and no money is forthcoming until all of the required documentation is obtained. It is no surprise then that participants, such as Hayley, emphasise the emotional strain and futility of trying to access welfare supports to which they are legally entitled (Hodgetts \& Stolte, 2017). They draw and talk openly about the stress, frustration, futility and anger they experience in having to weave the various agencies depicted in Figure one together to create some semblance of a service landscape for themselves. In a previous publication we theorised such relationships between welfare recipients and agencies using the concept of structural violence (Hodgetts et al., 2014).

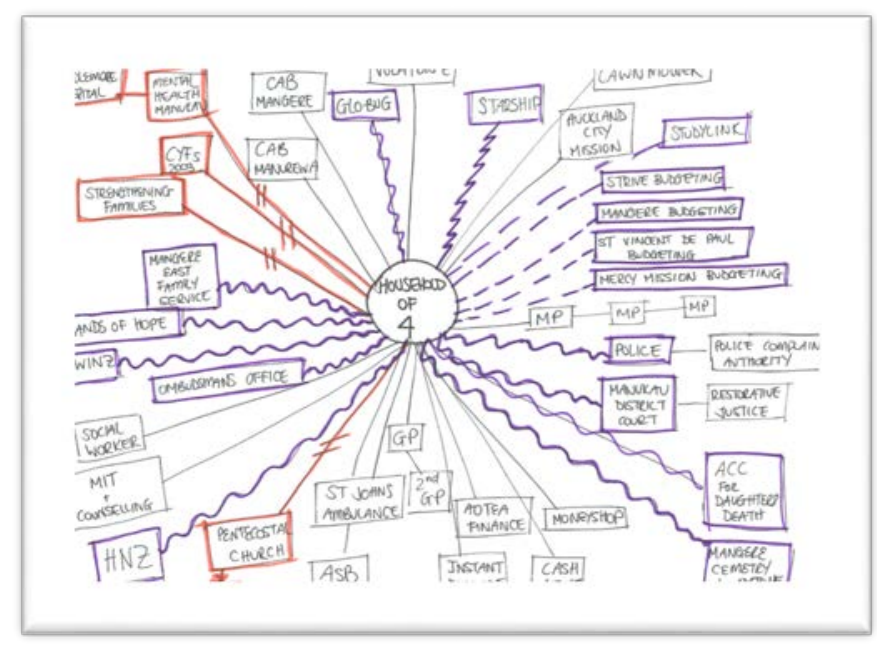

Figure one: Welfare service map

Psychological researchers frequently pride themselves on being more objective than other social science disciplines, by offering a supposedly unbiased account of their data. Yet, such an approach can limit analyses to description or partitioned cause-effect occurrences. Instead, we advocate for the need to 'go beyond your data' in order develop interpretations of artefacts such as the one featured in Figure one, which uncover the traces 
of the general buried within a particular image or account. Theoretical generalisation enables us to situate this service map as a starting point for moving beyond a description of dysfunctional relationships between Hayley and services to interpreting what is going on at an institutional societal level.

We can use theoretical abstractions to cultivate our impressions of the reasons why the welfare system is increasingly dysfunctional, inhumane and brutal to people such as Hayley. We begin by thinking creatively and by bringing various abstractions to bear in order to take us beyond the frame of Figure one. This aids us in situating this map societally and ideologically. Folding scholarship on neoliberalism, structural violence and penal welfare into our developing impression of the map and Hayley's associated account enables us to speak to broader societal issues of welfare retrenchment that extends beyond our shores. We can consider what Hayley's everyday engagements with agencies can tell us about contemporary welfare policies and practices that emphasise conditional support, rather than citizenship and rights (Hodgetts \& Stolte, 2017). The broader relevance of the service map in Figure one is highlighted by drawing on a wide palette of theoretical constructs. In this case, we connect the interactions evident in Figure one to institutionalisation of 'penal welfare' (Wacquant, 2009), structural violence (Hodgetts et al., 2014), denizens (Bauman, 2004) and the rise of the new precariat class (Standing, 2011). These overlapping theoretical concepts help to paint a picture of international shifts and intergroup politics that have meaning as exemplars beyond the individual instance (Flyvbjerg, 2006). Such theoretical concepts, which originate in North America and Europe, are used to inform our understanding of why people in New Zealand must engage with a chaotic and fragmented service landscape in order to gain basic necessities in life. Conversely, the exemplars (including Figure one) we use from New Zealand inform international debates regarding these theories. Through theoretical generalisation we can relate the experiences of our participants in New Zealand at the abstract level to those in other OECD nations also experiencing the rise of penal welfare and the denizening of people living in poverty. The resulting enhanced theorising of poverty can then be redeployed in further research across a range of contexts.

Theoretical generalisation from artefacts such as Figure one can also be purposed to extending efforts to conceptualise the psychological processes via which participants produce such artefacts to share their everyday experiences to us. In our case, this process is enabled through our use of Benjamin's concepts $(1933 / 1978,1982)$ such as mimesis and the dialogical image, which speak to the human propensity to create objects that approximate, reproduce and mimic aspects of their circumstances, experiences and practices (Hodgetts et al., 2018). These concepts when combined with notions of phronesis can enable us to think more directly about how, through the production of such objects 
people can work to know and share insights into their own lifeworlds. These concepts and others can be used to open up vantage points on such drawings via which we can recognise the efforts of human beings to make sense of, picture and communicate what it is like to live in poverty and have to engage with welfare services. Such concepts extend our reflexive understandings of what we are doing methodologically. As a result of our theoretical generalisation efforts in the methodology space, we have become particularly interested in picturing as a communicative practice that is used by participants to invoke the aspects of hardship that are hard to put into words alone (Hodgetts et al., 2018). Consideration of their efforts to let us know what is going on also leads to further abstract and concrete consideration of the increased difficulties surrounding intergroup communication between groups in the city.

This conceptual orientation is crucial for impressionisitic analysis because memetic objects such as that depicted in Figure one remain incomplete and merely hint at, but never fully capture what everyday life in poverty is like for someone. It also enables us to better understand participant difficulties in showing and telling us about hardship in a society that often blames them for their situations. This, in turn has led us to consider the dialogical potential of images (Benjamin, 1940, 1982), and how participant picturing practices can render their hardships more tangible for audiences living very different lives. In grappling with similar theoretical concerns, Benjamin (1940) states:

For what do we know of street corners, curb-stones, the architecture of the pavement - we who have never felt heat, filth, and the edges of stones beneath our naked soles, and have never scrutinized the uneven placement of the paving stones with an eye toward bedding down on them.

In adopting an impressionist approach, we do not seek to produce a definitive interpretation of Figure one. Rather we seek to theorise with this memetic snippet in order to conceptualise poverty in ways that embrace and situate everyday experiences systemically. We can engage intellectually with participant's agentive efforts to make sense of and communicate deeply felt experiences of hardship and futility, which are hard to put into words alone. Comprehending the pictures our participants create to 'show' and 'tell' us about their situations requires dialogue through which we move outwards beyond our data (pictures and accounts) to consider the more general societal significance of what they depict (Hodgetts, Radley \& Chamberlain, 2007). In engaging such issues, we are looking from within, but also out beyond the frames of pictures.

Finally, our use of the theoretical construct of the conduct of everyday life in the beginning of this chapter reflects how seamlessly we can bring general abstractions to bear 
on the particular, and in doing so speak from the particular to the general. Maps such as that depicted in Figure one elicit more in-depth commentary about the phronetic practices our participants employ to try and piece a workable welfare system together for themselves. Ultimately, theoretical generalisation is extremely useful in providing analytic tools that facilitate our thinking about, and evolving understandings of particular objects and accounts produced by research participants and the broader intergroup relations at play in these 'still objects'. Correspondingly, our approach to generalisation does not end with theoretical abstractions. As we will now demonstrate processes of generalisation are also of fundamental importance to action, and efforts to not only understand, but to also address issues of poverty. This takes us into the related forms of referential and empathetic generalisation.

\section{Referential generalisation}

Our approach to referential generalisation is based, in many respects on the assertion that poverty is created within a social world that features dysfunctional intergroup relations and institutional practices. We also propose that it is important that we do not extract experiences of poverty from this context. To do so is to risk individualising poverty and engaging in the age-old practice of victim blaming (Hodgetts \& Stolte, 2017). Referential generalisation involves efforts to engage with the social universe at play in the situations, people, practices and objects the populate participant pictures and accounts of everyday life. Such generalisation work often begins with engagements with specific artefacts such as the service diagram in Figure one. It also involves working with images that participants may have plucked from other sources such as the internet in order to convey aspects of their experiences or to render these /material and therefore real (see Figure 2). Such seemingly inanimate objects carry aspects of the broader social milieu from which they emerge and need to be analysed as such.

Referential generalisation enables us to ground structurally-orientated explanations for poverty, which implicate broader problems such as elite greed, with increased inequalities in society and the hardships experienced by our participants (Hodgetts \& Stolte, 2017). It is a form of generalisation where we seek the societal through the local. This is appropriate if one accepts that: "The general content is thus not dissolved into a multitude of empirical facts but is concretised in a theoretical analysis of a given social configuration and related to the whole of the historical process of which it is an insolvable part" (Horkheimer, 1941: 22). Through referential generalisation objects such as Figures one and two can be rendered as situational representations (Delmar, 2010), which are useful in grappling with 
the double articulation of the general in the particular. Practically, this requires a series of interpretive shifts out from particular artefacts, such as a 'GLOW-BUG' household electrical usage meter (Figure two), through which such objects are positioned as artefacts of broader inequitable socio-economic relations. In making these shifts, we are able to bring into sharper view the often less visible ways in which intergroup power relations texture poverty at the personal level of everyday life.

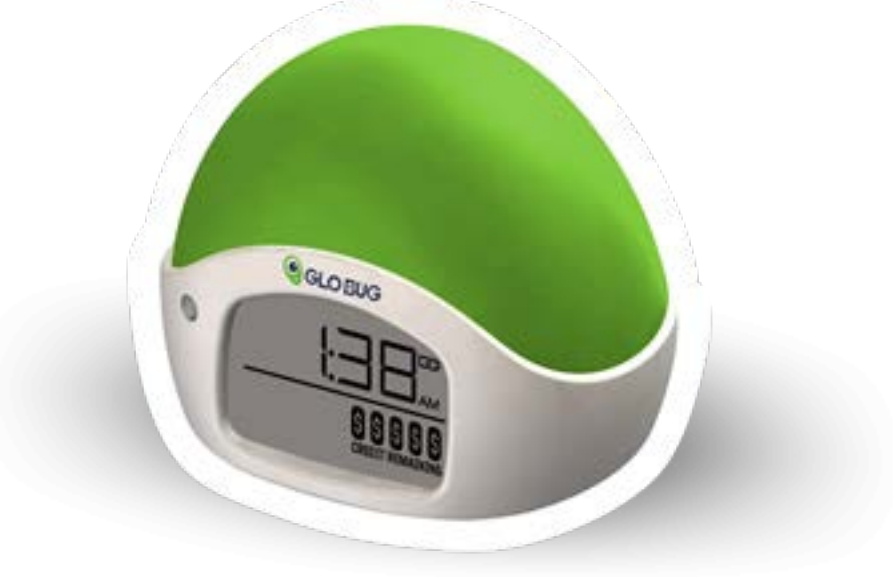

Figure 2: GLO-BUG power meter

In considering such shifts, let us consider Greg's account of the GLO-BUG and how this device regulates electricity usage in his household. By way of further context, the GLOBUG is a prepaid electricity device intended as a last resort for consumers with a bad credit history. The prepay costs of power are higher than the rates charged to post-pay electricity users. Greg's use of the image in Figure two when talking about his use of electricity positions the device as a metonym for hardships he endures. Inadequate funds mean that Greg must practice restraint in his everyday use of electricity, which then results in him having to choose between darkness or living in a cold, damp dwelling. Initially, Greg begins by talking about how:

It's just too expensive with running a 2000 watt heater for a few hours. You're paying near to 30 bucks a week... If you're not keeping an eye on it, it could be 35 bucks a week... Make sure you don't have the heater on because you can use a 2000 watt heater for an hour and that will be all your light usage for 24 hours...

Greg then invokes the GLO-BUG to exemplify how his practices of rationing and vigilance reflect the exacerbation of constants that have come into his home with this device. The GLOW-BUG is presented as an unwelcome and overly controlling addition to the household: 
You know that you can't deal with it on GLO-BUG... It's just a pre-pay phone card type of thing... And you put a minimum of 20 bucks, it costs $\$ 1.50$ to put in every time... If you get below $\$ 11.00$ they cut you off... They'll give you a warning and some stupid lights... When it's green, it's fine. When it's orange, you're power's low. It's going to be off in two days. When it turns red your power's going to be cut off at 12 o'clock... It drives you a little bit nutty...

Greg pitches his account at the level of everyday experience, anchored in relation to the electrical meter, his need for restraint, and the stressful and unhealthy circumstances in which he resides. Through this account we can see how his use of the GLO-BUG involves much more than a simple consumption practice. The extent to which this object intrudes on his everyday life is dehumanising in that the GLO-BUG regulates lighting, heating and when householders go to bed. This household object has become an unwelcome companion that constantly reminds Greg of the hardships, stress and anxieties of poverty. Greg's account also offers an everyday reference point to step out from in our analysis to consider further how his situation came to be.

Our orientation towards referential generalisation attunes us to the GLOW-BUG being more than an isolated inanimate object in Greg's home. To understand how this object and Greg's practices of restraint came into being we need to look at the underlying intergroup and institutional relationships that manifest in his home with this device. This focus is important because the GLO-BUG is part of a larger societal whole. The very existence of the GLO-BUG is comprises more than some objective effort to meet a specific consumer demand. There is a direct relationship between Greg's everyday experiences of restrained power use, the partial privatisation of New Zealand state owned electricity companies, and the investment practices of more affluent groups who seek financial returns from the use of such devices. Also implicated is the rise of penal welfare, which has resulted in reduced welfare support to pay for increased electricity prices. In this context, the GLOWBUG is knowable, and takes form through exploitative relationships between more wellheeled investors, the partially privatised electricity company, and consumers such as Greg. We read the meter as an artefact of extractive social hierarchies through which investors demand financial returns from power companies that extract these returns from people such as Greg. These relationships are central to the network of involvements or 'referential whole' within which the meter has emerged as a socio-political object (Heidegger, 1927/1973). In presenting and talking about such objects, participants also locate themselves within the context of broader social structures, intergroup relations, and their agentive everyday practices of survival. 
A focus on referential generalisation exemplifies the importance of not simply moving from a consideration of specific experiences and objects to theoretical abstractions. Scholars can also resituate these everyday phenomena by considering the inequitable intergroup and socio-economic relations that give birth and utility to such objects. Working referentially, we can interrogate the social milieu through a focus on everyday experiences, objects and events that inhabit it. We can explore how depictions of, and references to, such objects work to invoke socio-economic hierarchies that texture the everyday lives of people in need. The re-telling of the relational origins and significance of such everyday objects invokes a labyrinth of social relations and practices that stretches out beyond the specific object (Miller, 2010). As Fine (2006, p. 94) writes,

...exemplars of social research that both sharpen and stretch across levels of analysis, interrogating the movements of power across history, structure, social relations and lives, and the theoretical understandings of the webbing that connects... In these works, no unit is too small to see the fingerprints of the world.

In the present context, the GLOW-BUG is a material fingerprint that comes to solidify or materialise aspects of an inequitable social order currently shaping everyday lives in poverty. The GLOW-BUG exemplifies how, in inequitable and exploitative societies, wealthy people are implicated in the hardships of less fortunate citizens.

Ultimately, referential generalisation involves efforts to bridge the personal and societal in the conduct of everyday life. This approach involves efforts to extend present knowledge of how the everyday objects and practices that populate people's lives reflect broader intergroup relationships in society. This is important because the everyday lives of hardship do not occur in a relational vacuum separate from the rest of society. Everyday lives in poverty are shaped by the actions of more affluent groups. As such, we would argue that referential analysis allows us to demonstrate how the poverty experienced personally by our participants is inherently relational in nature (Hodgetts \& Stolte, 2017). Through referential generalisation we do not seek to establish cause and effect relationships. Rather, we seek to re-situate our participants' everyday lives historically and socio-economically, so that we can understand how such situations of adversity came to be (Becker, 1998). This is also about taking seriously the idea that artefacts from everyday life are products of history. Objects such as those considered in this chapter can be understood in relation to the context of their invention and use within particular lifeworlds.

By immersing ourselves within the perspectives of our participants and their accounts of everyday practices of restraint that take form around particular objects, we can develop substantive knowledge about the implications of broader socio-economic relations in shaping 
everyday poverty (Jahoda, 1992). We can also highlight targets for change such as the operation of New Zealand's partially privatised power companies, and how these entities exacerbate hardship for people like Greg. Such exemplars afford resources for proactive change activities such as lobbying people in a position to influence such intergroup relationships. This takes us into the domain of empathetic generalisation as a basis for action and social change.

\section{Empathetic generalisation}

Referentially, we live in a world where Arnold Abbott, a 90-year-old WWII veteran can be arrested in Fort Lauderdale twice in a week for feeding homeless people. You might think, surely this is a case of isolated lunacy. Well no. Across the US, over 70 cities have passed ordinances that criminalize feeding homeless people. You might ask if this is just an American initiative? Again, no. Such policies have spread out from the US like a pandemic, and are influencing city authorities around the world (Hodgetts \& Stolte, 2017). For example, New Zealand conservative politicians regularly try to introduce ordinances to ban homeless people from city spaces and to stop others from helping them. Some New Zealand business owners even hose homeless people down with cold water in the dead of winter as a means of moving them on. What we refer to as empathetic generalization is central to our efforts to challenge such denizenising practices by lobbying decision-makers using images produced by our participants. As such central to processes of generalisation for us are issues of praxis. This work also reflects our desire to not simply engage in poverty tourism (Hodgetts \& Stolte, 2017). Getting involved and trying to help people at risk of further displacement is also necessary in order for us to avoid perpetuating the extractive relations central to the 'ruling psychology' of our times (Seedat, 2017).

Many of our efforts at empathetic generalisation are designed to reduce the social distance between groups and to promote more humane responses to poverty issues such as homelessness (Hodgetts et al., 2011). Here, what we refer to as empathetic generalization also resembles aspects of what Fine (2006) has termed provocative generalizability and Seedat (2017) terms witnessing. For us, this involves provoking domiciled readers, for example, to recognize and feel some affinity with the everyday experiences of homeless people, to consider issues of fairness and inequality, and to imagine different responses to homelessness. Referential generalization is a dynamic construct. In one sense, it occurs when participants create memetic objects that establish some recognition of the general common ground we share as human beings (Delmar, 2010). Through these objects we can empathise as fellow human beings with the stresses and frustrations less affluent people 
experience. As scholar activists, we have utilized processes of empathetic generalisation in presenting participant images to decision-makers as part of broader efforts to stimulate the emotional intelligence of decision-makers. This requires a reduction in social distance between groups and the establishment of some common ground from which the in-humanity of many punitive responses to homelessness can be recognized as such.

In presenting the images and accounts of homeless people to the Auckland City Council, we sought to spark more humane responses that address the issue of homelessness through more humane strategies. Central here are efforts to de-familiarize classist outsider understandings of homelessness by, for example, presenting common everyday practices relating to sleeping, eating and socializing that homeless people engage in just like everyone else in Auckland. However, the difference is that homeless people engage in these domestic practices in public spaces. The material we presented was designed to open up a liminal space (Watkins \& Shulman, 2008) in which to encourage these decision-makers who have never experienced being homeless to approach the issue as caring human beings who share common practices under different circumstances with homeless people. We wanted councilors and their staff to pause for a moment, witness homelessness more from the perspective of homeless people, and then to reflect and perhaps think differently about how we might respond. We wanted to encourage the audience to share in the everyday practices of street life however vicariously and to recognised the difficulties faced by homeless people (Watkins \& Shulman, 2008).

Reflecting the overlapping nature of our three forms of generalisation, we draw on aspects of theoretical and referential generalisation in our efforts to promote empathetic generalisation. By way of background to the example to follow, two of us were asked to speak to a city council about proposed measures to ban homeless people and regulate how people rendered assistance to them. We wanted to reframe the conversation by ensuring that our dialogue was informed by the experiences of participants in our research. This involved presenting simple questions related to the everyday practices that populate homeless lifeworlds and then showing homeless people doing these 'normal' things in extraordinary situations (see Figure 3). The point of this exercise was to disrupt a punitive mind-set that was dominating official narratives at the time, and to enable these decisionmakers to recognise homeless people as human beings. We did this through depictions of them doing the very things we all do each day, which the audience would likely recognise. Briefly, our effort as scholar activists involved the use of the materials presented in Figure three to lobby city councillors when they considered a ban on homeless people from the Auckland CBD. 
Where do you sleep?

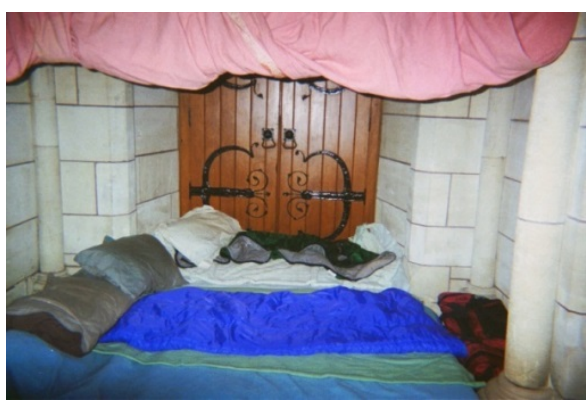

What about keeping the place tidy?

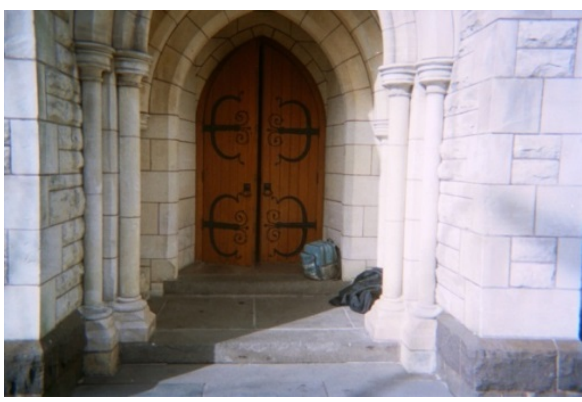

How do you keep clean?

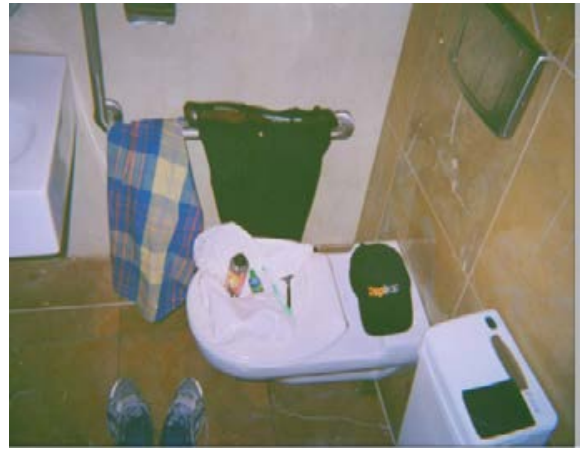

How do you make a living?

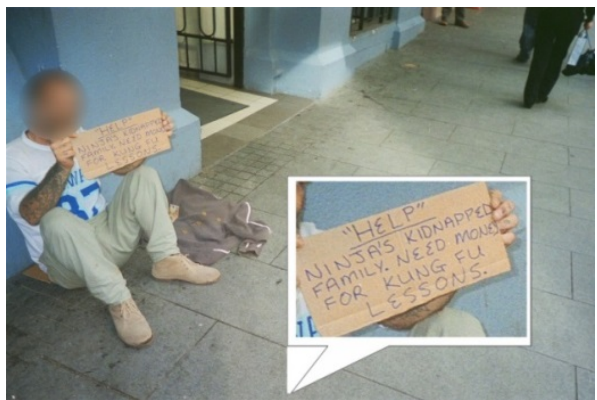

How do you get privacy?

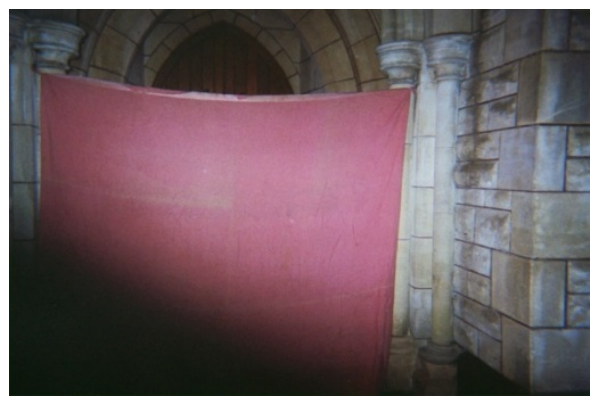

How do you cook on the streets?

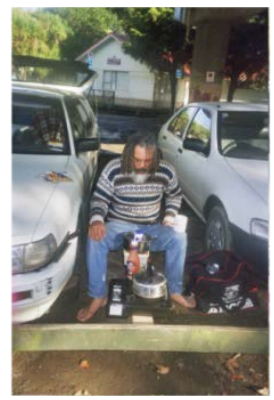

Where do you have social events?

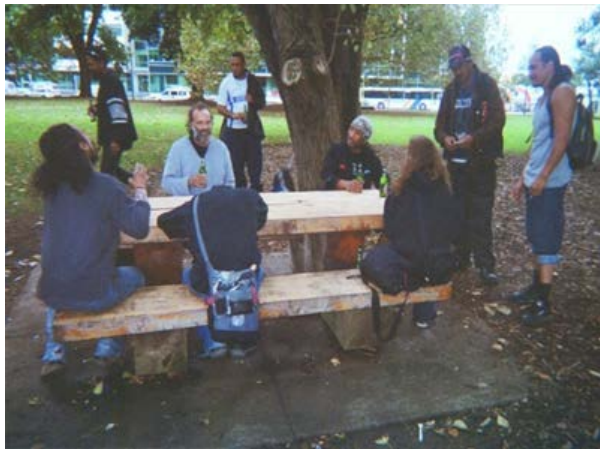

Figure three: Questions and Images from a workshop with city councillors

The questions and pictures in Figure three worked together much like music and lyrics to promote a shared emotional experience that is somewhat unique to each member of 
the audience. More broadly, these materials functioned to retexture the meeting space from a setting for planned exclusion to a setting for human inclusion in response to homelessness. The use of these questions and images worked to build a sense of familiarity and recognition that reduced the social distance between the city council audience and the homeless people depicted. We worked to not only promoted the recognition (Delmar, 2010) among decision-makers of the humanity of homeless people, but also to cultivate recognition that more humane responses were warranted. Plans to ban homeless people from the CBD and to regulate domiciled people who support homeless people were put on hold.

The current English meaning of the term 'sonder' is relevant to understanding what went on in this liminal space. Sonder is central to our understanding of empathetic generalisation. Sonder refers to the personal realisation of the richness of the existence of other people. It invokes the insight that like each of us, other people are living lives as rich and complex as our own. We all share a complex humanity. Sonder also invokes the idea that all of our lives are occurring all at once, often oblivious of each other. It is this obliviousness to the realities of homeless lives that we sought to rupture in the minds of city councillors. As noted in The Dictionary of Obscure Sorrows (Koenig, 2014), Sonder is:

the realization that each random passerby is living a life as vivid and complex as your own - populated with their own ambitions, friends, routines, worries and inherited craziness - an epic story that continues invisibly around you like an anthill sprawling deep underground, with elaborate passageways to thousands of other lives that you'll never know existed, in which you might appear only once, as an extra sipping coffee in the background, as a blur of traffic passing on the highway, as a lighted window at dusk.

Sonder requires a person slowing down and take more time to think about people affected by issues such as homelessness, and in ways that render homeless people more familiar and socially close. In cultivating sonder, we worked to promote in our city council audience a sense of shared humanity towards urban strangers, from which humane responses could be developed. In the context of scholarly considerations of generalisation, our promotion of Sonder epitomises the centrality of issues of action, and efforts to improve the everyday circumstances of people living in poverty. This exemplar also demonstrates how small acts that cultivate empathy and recognition through the creative use of research artefacts can have larger consequences for people on the margins of society.

Our efforts to promote sonder have synergies with recent work by Seedat (2017) on the centrality of a dialectical humanistic ethos in South African psychology and society. This involves embracing notions of empathy, witnessing, emotional immediacy, consciousness 
raising and social justice. Also central to Seedat's (2017) approach to developing more humane and engaged approaches to psychology is the enabling of people to see themselves again "...as caring and compassionate social actors..." (p. 523). For us, such work also involves developing human-centred ways of knowing poverty and homelessness that seek to challenge the inequitable social structures that shape the everyday lives of people affected.

\section{Conclusion}

This chapter has drawn on insights from several research projects exploring urban poverty and homelessness in partnership with the people concerned (Hodgetts et al., 2011, 2014, 2016, Hodgetts \& Stolte, 2017). A core goal in this chapter has been to exemplify our evolving approach to researching poverty in everyday life and beyond. Our impressionistic orientation is designed to enable us to link structural changes in society with the hurt and hardships experienced in a growing number of daily lives. Central to our approach is the assemblage of a series of fleeting glimpses produced by research participants into an impression of a larger social totality. Drawing insights from seminal scholars of social life, including Georg Simmel, Walter Benjamin, Marie Jahoda and Max Horkheimer, we have explored the broader societal significance of the scenes, experiences and relationships invoked by our participants through careful reflections on these fragments of everyday life. Like impressionist painters, we explore the general or societal through the particular or everyday (Davis, 1973; Horkheimer, 1941; Simmel, 1903/1971). This approach enables us to see hardship and homelessness as fundamentally relational elements of the social milieu.

In adopting an impressionist orientation, we are intentionally breaking from rule governed approaches to qualitative research such as discourse analysis, grounded theory and thematic analysis. Proponents of these approaches have dominated discussions of qualitative research in psychology. Such qualitative approaches have become popular, in part, because they offer the illusion of certainty through procedure that is very familiar to psychologists. These approaches do offer a set of procedures for beginning scholars to 'learn how to do analysis' and develop less tangible tricks of the trade (Becker, 1998). However, such approaches can also stifle creativity and reduce social analysis to a highly governed set of procedures. Central to established approaches that in many respects constitute a salon of qualitative research in psychology is the assumption that if one follows set procedures rigorously and employs 'the correct steps', then one can generate a plausible and hopefully even replicable analysis. We do not share this worldview. Rather than conducting micro-analyses of specific visual or verbal texts following a rigid set of coding 
strategies, our impressionistic analyses relies on our own experiences, creativity, instincts, and humanity of scholars. Our approach embraces the need for scholars to develop as virtuosos who are less rule governed (Flyvbjerg, 2006). It necessitates following hunches more than someone else's recipe for analysis. This is why we have not outlined detailed procedures for producing an impressionistic analysis. Far from constituting a set result, the impressions we construct of everyday poverty when employing an impressionistic orientation remains incomplete, partial, and open to further interpretation.

As well as focusing on the substantive issue of poverty we have also focused on issues relating to the communicability of everyday experiences of adversity. We have illustrated how research participants experiencing poverty actively re-construct and invoke hard and emotionally-textured everyday experiences that remain entangled within the grim actuality of being homeless or without sufficient funds to heat and dry one's modest dwelling. In order to help us understand what poverty is like, our participants provide creatively adulterated metonymic artefacts that come to resemble and stand in for their situations and experiences in general (cf., Benjiman, 1933/1978; 1940/2002; 1982). These objects offer selected slithers of everyday lifeworlds that point to, but can never full capture experiences of poverty. Correspondingly, we must go beyond viewing these artefacts as discrete units of data that hold set meanings in order to explore the structural and intergroup elements of poverty today. We move from these artefacts to consider the influence of more affluent groups in society in intensifying hardships enacted by people living in poverty. Our approach to such materials positions our participants as artisans in their own right who create memetic objects to render their experiences a little more tangible to us. For us poverty research is not simply a spectator sport. Central to efforts to generalise from what participants show and tell us are efforts to encourage different audiences to recognise the plausibility of the theoretical and referential generalisations we seek to make.

Our approach involves developing impressions that gain broader relevance when we shift our gaze out beyond the experiential level of daily living and onto the socio-economic relations that suffuse local settings. This is a crucial interpretive shift that can reveal the threads of inequitable relations that are entangled within the everyday lives of our participants (Hodgetts et al., 2014). Such an approach is particularly applicable to psychological scholarship on the conduct of everyday life, which asserts that human action exists simultaneously in both personal and communal life (Hodgetts et al., 2018). As scholars of the quotidian, we see our role as one of developing impressions of the underlying societal significance of local events for a society in motion (Simmel, 1900/1978/2004). We do this by capturing fleeting moments through the use of visual methods in order to consider the social relations and structures at play in shaping these particular scenes. Often fleeting 
memetic images of everyday situations afford anchor points for developing impressions of the broader phenomenon of poverty and homelessness that are reproduced in these local scenes. The resulting analysis is a play on the taken-for-granted, which documents and interprets as a means of defamiliarising harmful societal arrangements that are often normalised and taken-for-granted.

\section{References}

Bauman, Z. (2004). Wasted Lives. Modernity and its Outcasts. Cambridge: Polity.

Becker, H. (1998). Tricks of the Trade. Chicago: University of Chicago Press.

Benjamin, W. (1933/1978). On the mimetic faculty. In, Reflections: Essays, Aphorisms, Autobiographical Writings (pp. 333-336). (trans. E. Jephcott). New York: Schocken.

Benjamin, W. (1940/2002). The Arcades Project (H. Eiland, \& K. McLaughlan, Trans.). Cambridge, MA: Harvard University Press.

Benjamin, W. (1982). Illuminations. (trans. H. Zohn). London: Fontana.

Davis, M. (1973). Georg Simmel and the Aesthetics of Social Reality. Social Forces, 51(3), 320-329.

Delmar, C. (2010). "Generalizability" as recognition: Reflections on a foundational problem in qualitative research. Qualitative Studies, 1, 115-128.

Dreier, O (2016). Conduct of everyday life: Implications for critical psychology. In E Schraube and C. Hojholt (Eds.), Psychology and the Conduct of Everyday Life (pp. 1533). London: Routledge.

Fine, M. (2006). Bearing witness: Methods for researching oppression and resistance - A textbook for critical research. Social Justice Research, 19(1), 83-108.

Frisby, D. (1981). Sociological Impressionism: A Reassessment of Georg Simmel's Social Theory. London: Heinemann.

Flyvbjerg, B (2006). Five misunderstandings about case-study research. Qualitative Inquiry, $12,219-145$.

Flyvbjerg, B., Landman, T., \& Schram, S. (2012). Real social science: Applied phronesis. Cambridge: Cambridge University Press.

Goffman, I. (1963). Behavior in public places: Notes on the social orgainsation of gatherings. New York: Free Press. 
Halkier, B. (2011). Methodological practices in analytical generalisation. Quanlitative Inquiry, 17, 787-797.

Halkier, B., \& Jensen, I. (2011). Methodological challenges in using practice theory in consumption research. Journal of Consumer Culture, 11, 101-123.

Heidegger, M. (1927/1962). Being and Time. (trans. J. Macquarrie \& E. Robinson). London: SCM Press.

Hodgetts, D., Chamberlain, K. \& Radley, A. (2007). Considering photographs never taken during photo-production project. Qualitative Research in Psychology, 4, 263-280.

Hodgetts, D., Chamberlain, K., Groot, S., \& Tankel, Y. (2014). Urban poverty, structural violence \& welfare provision for 100 families in Auckland. Urban Studies, 51, 2036-2051.

Hodgetts, D., Groot, S., Garden, E., \& Chamberlain, K. (2016a). The precariat, everyday life \& objects of despair. In C. Howarth and E. Andreouli (Eds.). Everyday Politics. London: Palgrave.

Hodgetts, D., Groot, S., Chamberlain, K., \& Gardener, E. (2016b). Debt in the everyday lives of 100 families experiencing urban poverty in New Zealand. In C. Walker and S. Degirmencioglu (Eds.). Social and Psychological Dimensions of Personal Debt and the Debt Industry. Palgrave MacMillian: London.

Hodgetts, D., Drew, N., Stoltie, O., Sonn, C, Nikora, N., \& Curtis, C. (2010). Social Psychology and Everyday Life. Houndmills, Basingstoke: Palgrave/MacMillian.

Hodgetts, D. \& O'Doherty (2018). Introduction to Applied Social Psychology In K. O'Doherty and D. Hodgetts (Eds.), Sage Handbook of Applied Social Psychology. Sage: London.

Hodgetts, D. \& Stolte, O. (2017). Urban Poverty and Health Inequalities: A Relational Approach. London/New York: Routledge.

Hodgetts, D., Stolte, O., Groot, S., \& Drew, N. (2018). Homelessness, mimesis and the flânerie. International Perspectives in Psychology, xxx

Hodgetts, D., Stolte, O., Radley, A., Groot, S. Chamberlain, K. \& Leggatt-Cook, C. (2011). 'Near and far': Social distancing in domiciled characterizations of homeless people. Urban Studies, 48, 1739-1753.

Holzkamp, K (1995/2016). Conduct of everyday life as a basic concept of critical psychology. In E Schraube and C. Hojholt (Eds.), Psychology and the Conduct of Everyday Life (pp. 65-98). London: Routledge.

Horkheimer, M. (1941). Notes on Institute activities. Studies in Philosophy and Social Science, 9: 121-123. 
Jahoda, M., Lazarsfeld, P., \& Zeisel, H. (1933/1971). Mariethal: A Sociography of an Unemployed Community. London: Tavistock.

Jahoda, M. (1992). Reflections on Marienthal and after. Journal of Occupational and Organizational Psychology, 65, 355-358.

Koenig, J. (2014). The Dictionary of Obscure Sorrows. Accessed 13-3-18, https://www.youtube.com/watch?v=AkoMLO FiV4

Lévi-Strauss, C. (1962). The Savage Mind. Chicago: University of Chicago. Simmel, G. (1900/1978/2004). The Philosophy of Money (D. Frisby, Trans.). London: Routledge.

Miller, D. (2010). Stuff. Cambridge: Polity Press.

Seedat, M. (2017). Psychology and humanism in the democratic South African Imagination. South African Journal of Psychology, 47, 520-530.

Simmel, G. (1900/1978/2004). The Philosophy of Money (D. Frisby, Trans.). London: Routledge.

Standing, G. (2011). The Precariat: The New Dangerous Class. London: Bloomsbury.

Strauss, A. \& Corbin, J. (1994). "Grounded Theory Methodology." In NK Denzin \& YS Lincoln (Eds.) Handbook of Qualitative Research (pp. 217-285). Thousand Oaks, Sage Publications.

Wacquant, L. (2009). The body, the ghetto and the penal state. Qualitative Sociology, 32, 101-129.

Watkins, M., Shulman, H. (2008). Toward Psychologies of Liberation. London: Palgrave MacMillan. 